American Journal of Applied Sciences 3 (3): 1760-1762, 2006

ISSN 1546-9239

(c) 2006 Science Publications

\title{
Effect of ball milling times on phase formation of $\mathrm{Mg}_{0.7} \mathrm{Zn}_{0.3} \mathrm{Fe}_{2} \mathrm{O}_{4}$
}

\author{
Aurawan Rittidech and Panuthat Khotsongkram \\ Department of Physics, Faculty of Science, Mahasarakham University, Mahasarakham, Thailand
}

\begin{abstract}
Mg}_{0.7} \mathrm{Zn}_{0.3} \mathrm{Fe}_{2} \mathrm{O}_{4}$ (MZF) powder was prepared by a solid-state mixed oxide using ballmilling technique. The phase identification of calcined powders was performed using X-ray diffraction technique (XRD). It has been found that MZF powders were successfully obtained for calcination conditions of $800{ }^{\circ} \mathrm{C}$ for milling times of $36 \mathrm{~h}$, whereas milling times of $12 \mathrm{~h}$, unreacted $\mathrm{ZnO}, \mathrm{Fe}_{2} \mathrm{O}_{3}$ and $\mathrm{MgO}$ phases $\left(2 \theta \sim 54,57\right.$ and 63) are detected from the original mixture up to $900{ }^{\circ} \mathrm{C}$. By increasing the calcination temperature to $1000{ }^{\circ} \mathrm{C}$, a single phase of MZF is formed. Moreover, the microstructure of powder were examined by scanning electron microscopy (SEM) and showed that the particle in size from 58-1200 nm. While, XRD patterns were obtained average size of particle, calculation by Scherrer's equation, between $30.54-66.59 \mathrm{~nm}$.
\end{abstract}

Keywords: $\mathrm{Mg}_{0.7} \mathrm{Zn}_{0.3} \mathrm{Fe}_{2} \mathrm{O}_{4}$, ball-milling, calcination

\section{INTRODUCTION}

Magnetic ferrites were studied extensively due to their many applications. A candidate system of such a revisit is the mixed ferrites of $\mathrm{Zn}$ and $\mathrm{Mg}$ as magnesium-zinc ferrites $\left(\mathrm{Mg}_{1-\mathrm{x}} \mathrm{Zn}_{\mathrm{x}} \mathrm{Fe}_{2} \mathrm{O}_{4}\right)$. $\quad \mathrm{Mg}_{1-}$ ${ }_{x} \mathrm{Zn}_{\mathrm{x}} \mathrm{Fe}_{2} \mathrm{O}_{4}$ is one of a ferrites material, displaying interesting magnetic properties. The importance of ferrites is well realized in the fields of electronics and communication which has a wide range of magnetic coils and electronic devices [1]. It is found that magnesium-zinc ferrites fraction $\mathrm{x}$ between 0.2 to 0.3 were significantly obtained magnetic properties [2-3]. The crystal structure of these materials controls their properties. Then the magnetic properties of materials are sensitive to conditions of preparations. The preparations of materials by solid-state reaction route under ball milling technique are not complicate and inexpensive so they are suitable for mass product. Recently, many studies [3] indicated that X-ray diffraction were carried out for $\mathrm{Mg}$-ferrites, $\mathrm{Ni}$ - ferrites, $\mathrm{Ni}-\mathrm{Zn}$ ferrites, Ni-Mg ferrites, Mg-Zn ferrites, Ni-ZnMg ferrites.

The aim of this work is to study the effect of ball milling times on phase formation and microstructural development of $\mathrm{Mg}_{0.7} \mathrm{Zn}_{0.3} \mathrm{Fe}_{2} \mathrm{O}_{4}$ powders in order to find an optimum calcinations condition.

\section{EXPERIMENTAL PROCEDURE}

$\mathrm{Mg}_{1-\mathrm{x}} \mathrm{Zn}_{\mathrm{x}} \mathrm{Fe}_{2} \mathrm{O}_{4}$ powder with $\mathrm{x}=0.3$ was prepared from laboratory-grade oxides of zinc oxide
$(\mathrm{ZnO})$, ferric oxide $\left(\mathrm{Fe}_{2} \mathrm{O}_{3}\right)$ and magnesium oxide $(\mathrm{MgO})$. All raw materials have been prepared by a solid-state mixed oxide technique. In the mixing process, the calculated relevant proportions of constituents were weighed, suspended in isopropyl alcohol (IPA) and intimately mixed for different times in a ball-milling, for 12, 18, 24, 30 and 36 hours with metal media. Drying was carried out for $2 \mathrm{~h}$ (the sample dish was placed on a hotplate with a magnetic stirring in action to prevent gravitational separation of the components). The dried powder was then ground, sieved and calcined at temperature between 800$1200{ }^{\circ} \mathrm{C}$. XRD technique (XRD; Philips PW 1729 diffractometer) was used to identify the optimum firing temperatures, for phase identification, for quantitative analysis of mixtures of phases. The means crystallite size D was obtained from the Scherrer formula [4]:

$$
D=\frac{(k \lambda)}{(\beta \cos \theta)}
$$

where $\mathrm{k}=0.9, \lambda=1.541, \theta$ is the diffraction peak angle, and $\beta$ denotes the full width at half maximum of the corresponding diffraction peak. The particle sizes and morphologies of the powders have been directly imaged using scanning electron microscopes SEM and EDX (JEOL JSM-840A).

\section{RESULTS AND DISCUSSION}

All calcined powders together with that of the starting powder mixtures were examined by XRD in order to investigate the phase development (Fig.1 (a)(f)).

Corresponding Author: Aurawan Rittidech Department of Physics, Faculty of Science, Mahasarakham University, Mahasarakham, Thailand 44150, Tel: 043-754379, Fax: 043-754379 

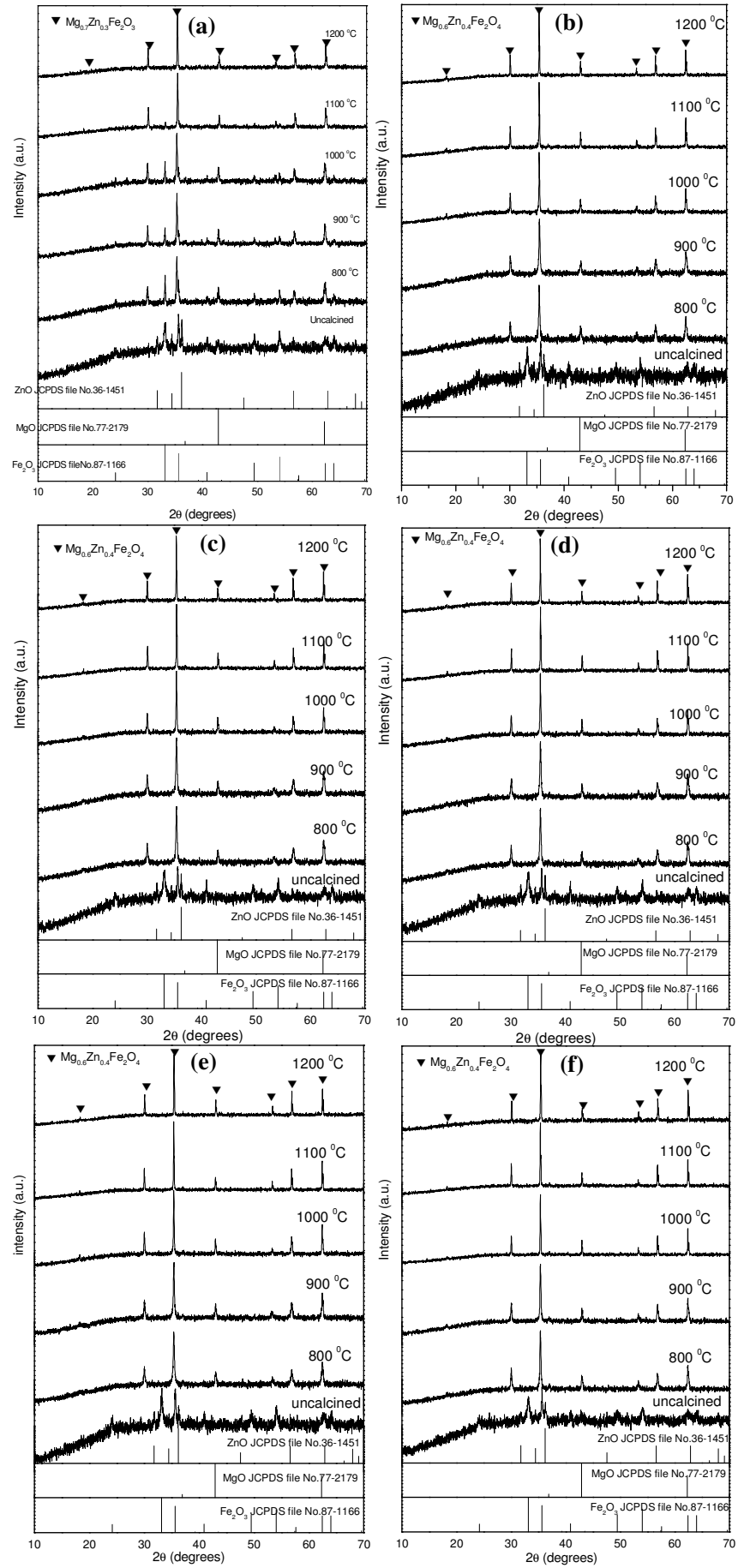

Fig. 1: XRD patterns of $\mathrm{Mg}_{0.7} \mathrm{Zn}_{0.3} \mathrm{Fe}_{2} \mathrm{O}_{4}$ powders calcined at various temperatures and different milling times (a) $0 \mathrm{~h}$, (b) $12 \mathrm{~h}$, (c) $18 \mathrm{~h}$, (d) 24 $\mathrm{h}$, (e) $30 \mathrm{~h}$, and (f) $36 \mathrm{~h}$.

As shown in Fig. 1(a), for non ball milling, XRD pattern of the uncalcined powder was showed peak of precursors $\mathrm{ZnO}, \mathrm{MgO}$ and $\mathrm{Fe}_{2} \mathrm{O}_{3}$. By increasing the calcinations temperature from 800 to $1200{ }^{\circ} \mathrm{C}$, the yield of the $\mathrm{Mg}_{0.7} \mathrm{Zn}_{0.3} \mathrm{Fe}_{2} \mathrm{O}_{4}$ phase increases significantly until at $1200{ }^{\circ} \mathrm{C}$, single phase of MZF is formed. Having established the optimum calcinations temperature, powders with ball milling times at $12 \mathrm{~h}, 18$ $\mathrm{h}, 24 \mathrm{~h}, 30 \mathrm{~h}$ and $36 \mathrm{~h}$ were calcined between at 800 and $1200{ }^{\circ} \mathrm{C}$, as shown in Fig. 1 (b)-(f), respectively. In Fig. 1 (b) -(f), the single phase of MZF were found to be possible in $1000{ }^{\circ} \mathrm{C}$ for time of milling at 12 and $18 \mathrm{~h}$, in $900{ }^{\circ} \mathrm{C}$ for time of milling at 24 and $30 \mathrm{~h}$ and in the last $800{ }^{\circ} \mathrm{C}$ for time of milling at $36 \mathrm{~h}$. The optimal calcination conditions for phase of MZF is interested at two conditions, one at the short time of milling with $12 \mathrm{~h}$ which is calcined at $1000{ }^{\circ} \mathrm{C}$ and other at the long time of milling with $36 \mathrm{~h}$ which is calcined at $800{ }^{\circ} \mathrm{C}$. This result was showed for the milling time which is optimized to fine powders; these can be matched with heat treatment for MZF phase formation.

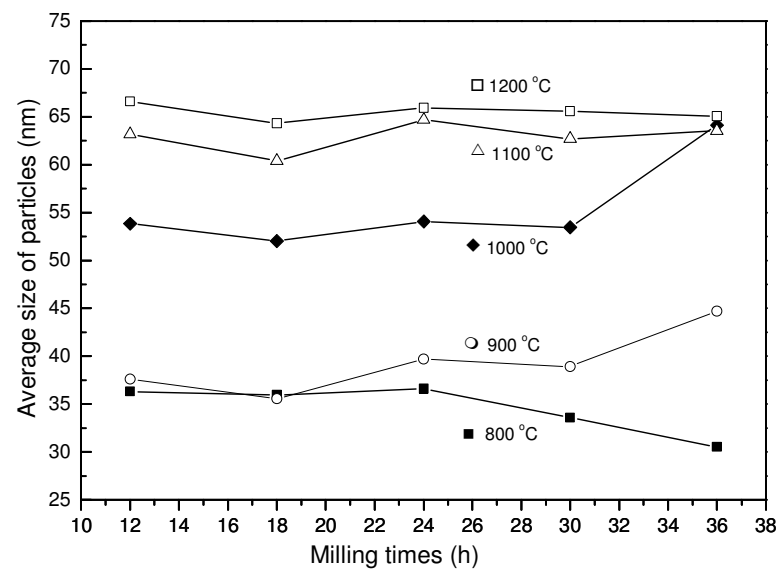

Fig. 2: The relationship of average particles size from Scherrer's equation and milling times with different calcination.

From XRD patterns were obtained average size of particle, calculation by Scherrer's equation, between $30.54-66.59 \mathrm{~nm}$ and the relationship between particle size of all samples as a function of the calcination conditions and milling times are shown in Fig. 2. SEM shows the morphological evolution (Fig. 3 ), these result indicates that degree of grain size tend to increase with higher calcination temperature and the particles are decreased in shape with samples milled for longer time. The MZF particle size estimated by SEM micrographs as between $58-1200 \mathrm{~nm}$ and it is different in size by Scherrer's equation since Scherrer's equation is calculated from XRD patterns while SEM micrographs are calculated from selected area in sample.In general, similar morphological characteristics were observed in these powders, i.e. agglomerated and basically irregular in shape. EDX analysis and chemical 
compositions for some MZF of these powders are shown in Fig. 4. As shown in Table 1 can be confirmed the parent of compositions to be MZF.
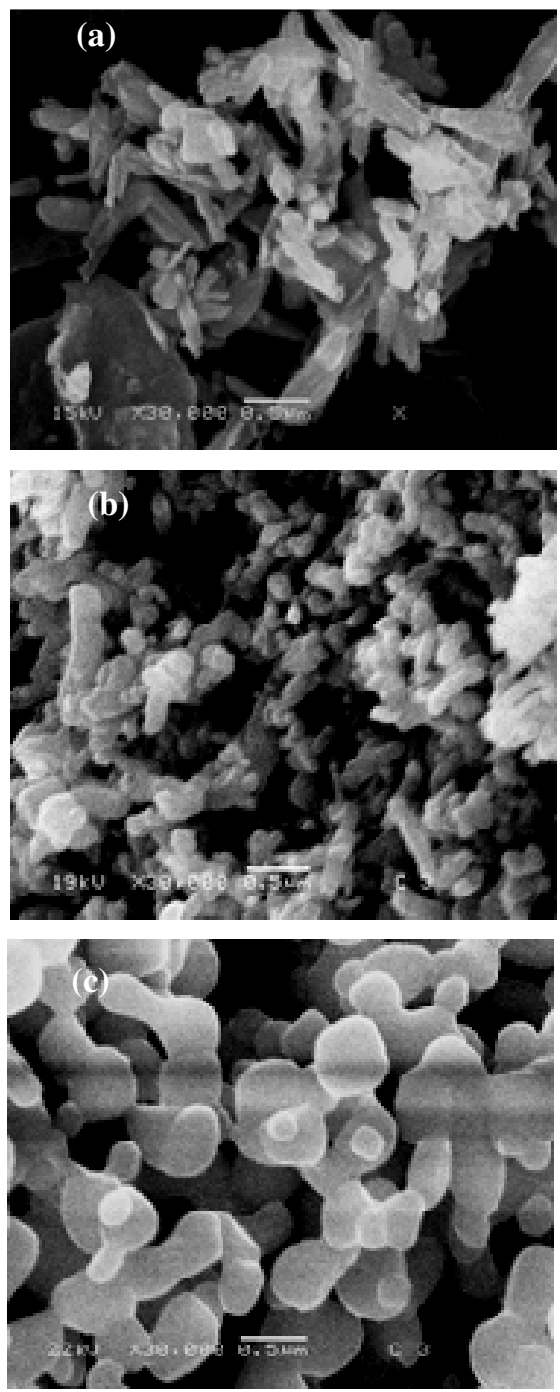

Fig. 3: SEM micrographs of MZF different conditions

(a) non ball milled with uncalcined

(b) milled for $12 \mathrm{~h}$ with calcined at $800{ }^{\circ} \mathrm{C}$

(c) milled for $12 \mathrm{~h}$ with calcined at $1000{ }^{\circ} \mathrm{C}$.

Table 1: Chemical compositions of the MZF powders from EDX analysis calcined at;

(a) $1000{ }^{\circ} \mathrm{C}$ with milling of $12 \mathrm{~h}$

(b) $800{ }^{\circ} \mathrm{C}$ with milling of $36 \mathrm{~h}$.

\begin{tabular}{lcccc}
\hline \multirow{2}{*}{ Samples } & \multicolumn{4}{c}{ Compositions (at\%) } \\
\cline { 2 - 5 } & $\mathrm{Fe}(\mathrm{K})$ & $\mathrm{Zn}(\mathrm{K})$ & $\mathrm{Mg}(\mathrm{K})$ & $\mathrm{O}(\mathrm{K})$ \\
\hline MZF (a) & 28.69 & 5.14 & 10.83 & 54.44 \\
MZF (b) & 34.57 & 5.95 & 8.89 & 49.82 \\
\hline
\end{tabular}
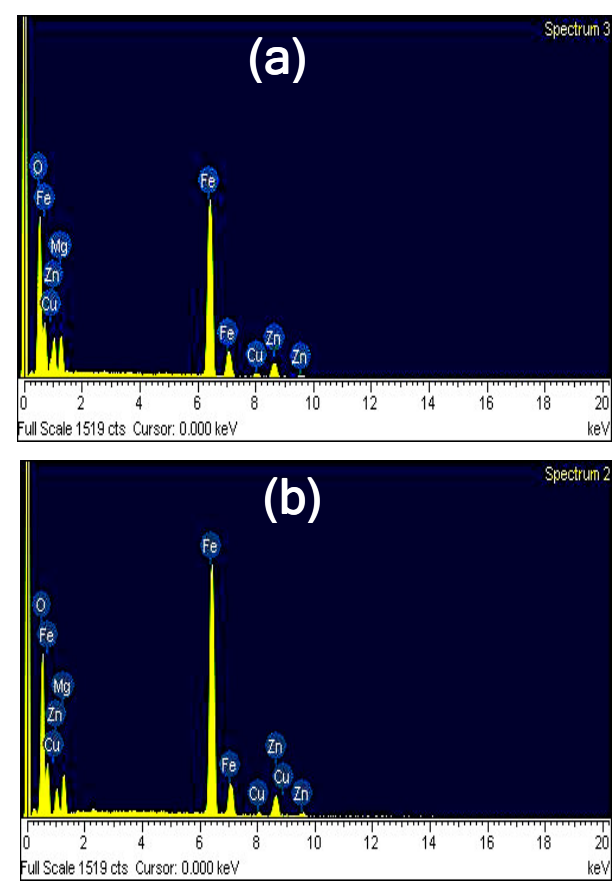

Fig. 4 EDX analysis of the MZF powders milling for

(a) $12 \mathrm{~h}$ and calcined at $1000{ }^{\circ} \mathrm{C}$

(b) $36 \mathrm{~h}$ and calcined at $800^{\circ} \mathrm{C}$.

SUMMARY

Single phase of MZF may be produced by solid state reaction via ball milling technique. The optimal calcination conditions for phase of MZF is obtained from two conditions, one at $1000{ }^{\circ} \mathrm{C}$ for milling time of $12 \mathrm{~h}$ and other at $800^{\circ} \mathrm{C}$ for milling time of $36 \mathrm{~h}$. The MZF particle size estimated by SEM micrographs as between 58-1200 nm, while from XRD patterns were obtained average size of particle, calculation by Scherrer's equation , between $30.54-$ $66.59 \mathrm{~nm}$.

\section{ACKNOWLEDGEMENTS}

The authors express their sincere appreciation to Mahasarakham University, Thailand for the support.

\section{REFERENCES}

1. Rezlescu, N., E. Rezlescu, P.D. Popa, M.L. Craus and L. Rezlescuy, 1998. Copper ions influence on the physical properties of a magnesium-zinc ferrite. J. Magnet. and Magn. Mater., 183: 199-206.

2. Chandrasekaran, G. and P. Nimy Sebastian, 1998. Magnetic study of $\mathrm{Zn}_{x} \mathrm{Mg}_{1-x} \mathrm{Fe}_{2} \mathrm{O}_{4}$ mixed ferrites. Mater. Lett., 37: 17-20.

3. Amer, M.A. and M. El Hiti, 2001. Mossbauer and X-ray studies for $\mathrm{Ni}_{0.2} \mathrm{Zn}_{\mathrm{x}} \mathrm{Mg}_{0.8 \mathrm{-}-\mathrm{Fe}} \mathrm{Fe}_{2} \mathrm{O}_{4}$ ferrites. $\mathrm{J}$. Magnet. and Magn. Mater., 234: 118-125.

4. Rao, P., M. Iwasa, J. Wu, J. Ye and Y. Wang, 2004. Effect of $\mathrm{Al}_{2} \mathrm{O}_{3}$ additio o $\mathrm{ZrO}_{2}$ phase composition in the $\mathrm{Al}_{2} \mathrm{O}_{3}-\mathrm{ZrO}_{2}$ system. Ceram. Int., 30: 923-926. 